\title{
Yetişkinlerde Gıda Etiketi Okuma Bilgi Düzeyi ile Davranışa Geçirme Arasındaki İlişki
}

\section{The Relationship Between the Level of Knowledge of Reading Food Label and Acquisition in Adults}

\author{
${ }^{1}$ Mervenur GÖKÇEN, ${ }^{1}$ Aylin SEYLAM KÜŞÜMLER \\ ${ }^{1}$ İstanbul Okan Üniversitesi, Beslenme ve Diyetetik Bölümü, İstanbul, Türkiye \\ Mervenur Gökçen: https://orcid.org/0000-0002-3624-1952 \\ Aylin Seylam Küşümler: https://orcid.org/0000-0003-4705-8042
}

\section{ÖZ}

Amaç: Çalışmada yetişkin bireylerin gıda etiketi okuma bilgi düzeyi ile bu bilginin davranışa geçirilmesi arasındaki ilișkiyi değerlendirmek amaçlanmıștır.

Materyal ve Metot: Çalışma Türkiye'deki 19 yaş üstü çalışan ve çalışmayan kesimden 401 bireyle gerçekleştirilmiştir. Geçerli ve güvenilir bir ölçek olan "Gıda Etiketi Okuma ve Sağlık Algılama Bilgi Düzeyi Ölçeği”" çalışmanın amacına göre düzenlenip kullanılmıştır.

Bulgular: Çalışmadaki 401 katılımcının yaş ortalaması $38,85 \pm 0,57$, "bilgi düzeyi" puan ortalamas1 $9,42 \pm 2,10$, "davranışa geçirme" puan ortalaması 7,02 $\pm 3,89$ olarak saptanmıștır. Beslenme hakkında danışmanlık alan bireylerin almayanlara göre daha fazla bilgisi olmasına rağmen bilginin davranışa geçirilmesinde anlamlı fark bulunamamıștır ( $p>0,05$ ). Kadın katılımcıların etiket okuma bilgi düzeyi erkeklerden daha fazlayken davranışa geçirmede anlamlı fark bulunamamıștır $(\mathrm{p}>0,05)$. Eğitim düzeyi arttıkça bilgi düzeyi artar sonucuna varılmış $(p<0,05)$, fakat düşük eğitim düzeyindeki bireylerin yüksek eğitim düzeyindekilere göre bilgilerini davranışlarına daha çok yansıttığı saptanmıştır $(\mathrm{p}<0,05)$. Beden kitle indeksi faktörüne göre bilgi düzeyinde ve davranışa geçirilmesinde anlamlı fark bulunamamıştır ( $\mathrm{p}>0,05)$.

Sonuç: Çalışmada yetişkinlerin gıda etiketi hakkında bilgi sahibi oldukları, fakat bu bilgilerini davranışlarına yansıtamadıkları tespit edilmiştir. Bireylerin sahip oldukları bilgileri davranıșa geçirebilmeleri için bilinçlendirici eğitim politikaları geliştirilerek bireylerin farkındalığ 1 artırılmalıdır.

Anahtar Kelimeler: Bilgi, davranış, gıda etiketlemesi, obezite

\section{ABSTRACT}

Objective: This study was conducted to evaluate the relationship between the food label reading knowledge of individuals over 19 years old and the transmission of this information into behavior.

Materials and Methods: The study was carried out with 401 working and nonworking individuals around Turkey over 19 years of age. "Food Label Reading and Health Perception Level of Knowledge Scale", a valid and reliable scale, was arranged and used according to the study's purpose.

Results: The average age of the 401 individuals was $38.85 \pm 0.57$, "knowledge level" was $9.42 \pm 2.10$, and "conversion to behavior" was $7.02 \pm 3.89$. Although individuals who received nutrition counseling had more knowledge than who did not, no significant difference was found in the conversion of knowledge to behavior $(p>0.05)$. Females label reading knowledge was higher than that of men, with no significant difference in behavior $(p>0.05)$. It was concluded that the higher the education level, the higher the level of knowledge $(p<0.05)$, but it was found that individuals with low education levels reflected their knowledge into behavior more than those with higher education levels $(p<0.05)$. According to the body mass index, there was no significant difference in the knowledge level and the conversion to behavior ( $\mathrm{p}>0.05$ ).

Conclusion: In the study, it was determined that the adults had information about the food labels, but could not reflect this knowledge into behavior. The awareness of individuals should be increased by developing awareness-raising education policies so that individuals can use their knowledge to act.

Keywords: Behavior, food labeling, knowledge, obesity
Sorumlu Yazar / Corresponding Author:

Mervenur Gökçen

Tepeören Mahallesi Tuzla Kampüsü, İstanbul Okan Üniversitesi, 34959, Tuzla/İstanbul

Tel: +90 (216) $6771630 /+905343616757$

Fax: 0 (216) 6771647

E-mail: mervenurgken@gmail.com
Yayın Bilgisi / Article Info:

Gönderi Tarihi/ Received: 13/09/2020

Kabul Tarihi/ Accepted: 09/02/2021

Online Yayın Tarihi/ Published: 05/03/2021

Atıf / Cited: Gökçen M, Seylam Küşümler A. Yetişkinlerde Gıda Etiketi Okuma Bilgi Düzeyi ile Davranışa Geçirme Arasındaki İlişki . Online Türk Sağllk Bilimleri Dergisi 2021;6(1):82-91. doi: 10.26453/otjhs.794408 


\section{GÍRIŞ}

Tüketiciler gıdaların güvenilirliğine, gıda öğesi içeriğine ve sağlıklı olmasına önem vermektedir. ${ }^{1}$ Tüketici sağlığı açısından önemli bir faktör, gıda etiketinin doğru okunup yorumlanmasıdır. ${ }^{2}$ Enerjisi fazla olan kolay ulaşılabilir, düşük maliyetli hazır gıdaların tüketiminin artışı, sağlıklı gıda seçimindeki bilgi açığı gibi durumların sonucunda vücutta aşırı yağ birikimi olan obezite kaçınılmazdır ve kronik hastalıklar ile bazı kanser türlerine sebep olabilir. ${ }^{3-7}$

Tüketici sağlığında önemli bir etken olan gıda etiketi; gıda maddesini tanıtıcı her türlü yazılı veya basılı bilgi, damga, marka ve işaretleri içeren ve gıda ile sunulan veya ambalajında basılı olan tanıtım bildirimidir. ${ }^{8}$ Gida etiketlerinde, önce toplam ve bir porsiyonluk miktarları, sonrasında detaylı gıda öğesi bilgileri verilir. Gıda etiketleri; tüketicilerin yeterli ve dengeli beslenmeleri için, özel diyet programlarında (gıda alerjileri, çölyak vb.) ve en sağlıklı gıda seçimi yapabilmelerinde etkili olabilmektir. ${ }^{9}$ Türk Gıda Kodeksi Etiketleme Yönetmeliği'ne göre gıdanın adı, net miktarı, bileşenler veya bileşen gruplarının miktarı, alerjen bileşenler, tavsiye edilen tüketim tarihi, özel saklama koşulları, menşe ülke gibi bilgilerin gıdaların etiketinde yer alması zorunludur. ${ }^{10}$

Tüketicilerin yaş, cinsiyet, eğitim gibi özellikleri gıda etiketini okumada etkilidir. ${ }^{11}$ Ayrıca kişilerin sağlıklı beslenmeye duydukları ilgiye ve beslenme bilgi düzeylerine göre etiket okuma sıklığının değişebileceği belirlenmiştir. Ancak sağlıklı ürün seçiminde bilgi açığı olduğu tespit edilmiştir. ${ }^{1}$ Gida tüketim davranışlarını etkileyen diğer faktör, kişilerin öncelikli değerleridir. Önem verilen değerlerin, en azından kısa sürede değiştirilmesi imkanı olamadığından, tüketicileri etiket okumaya teşvik edecek, bu alışkanlığı kazandıracak çözüm yolları bulunmalıdir. ${ }^{11}$

Etiket bilgisi okuma alışkanlığı kazandırmada çözüm yollarından biri, etiketlerin hızlı ve kolay anlaşılabilecek, standart ve basit şekilde sunulması olabilir. ${ }^{11}$ Ayrıca etiket okumayla ilgili televizyonda yayınlanacak programların tüketicilerin bilinçlendirilmesinde önemli katkıları olacaktır. ${ }^{12}$

Çalışmanın amacı; yetişkinlerin beslenme danışmanlığı alma/almama, cinsiyet, beden kitle indeksi (BKİ), eğitim durumu değişkenlerine göre gıda etiketi okuma bilgi düzeyi ile davranışa geçirme arasındaki ilişkiyi ortaya koymak ve konuyla ilgili farkındalığı artırmaktır.

\section{MATERYAL VE METOT}

Etik Kurul Onayı: Araştırmanın yapılabilmesi için İstanbul Okan Üniversitesi Etik Kurulu'ndan (Karar Tarih/No: 14/06/2020/ 56665618-204.01.07) izin alınmıştır. Çalışma uluslararası deklerasyona, kılavuz vb. uygun gerçekleştirilmiştir.

Araştırmanın Tipi: Bu çalışma tanımlayıcı ve kesitsel tiptedir.

Araştırmanın Evren ve Örneklem Seçimi: Çalışmada etiket okuma alışkanlığının ileri yaşlarda daha yaygın olduğu öngörüldüğünden 19 yaş üstü yetişkin bireyler tercih edilmiştir. Türkiye İstatistik Kurumu'nun $^{13} 2000$ yılına ait verilere göre Türkiye'de 19 yaş üstünde 40.374 .357 birey vardır. $\mathrm{Bu}$ bireyler araştırmanın sonlu evrenini oluştururken; çalışma kapsamına alınacak, çalışmaya katılmayı kabul eden 19 yaş üstü bireyler araştırmanın örneklemini oluşturur. Raosoft Sample Size Calculator programıla yapılan hesaplamalara göre, $\% 95$ güven için düzenli dağılımla en az 385 kişinin araştırmaya katılımı hedeflenmiştir. Katılımcı sayısında hedefin üzerine çıkılarak, çalışma 401 bireyle gerçekleştirilmiştir. Katılımcıların büyük bir kısmı $\% 65,8$ oran ile İstanbul'dan, \%13,8 oran ile Ordu'dan olmakla birlikte diğer illerden de katılım gösterilmiştir. Anketin uygulanacağı bireyler rastgele yöntem ile belirlenmiştir.

Veri Toplama Araçları: Araştırma verileri "Gıda Etiketi Okuma ile Sağlık Algısı Bilgi Düzeyi Ölçeği” çalışmanın amacına göre düzenlenerek toplam 38 sorudan oluşan bir anket ile toplanmıştır. ${ }^{14}$ Ölçek kullanımına ilişkin gerekli izin alınmıştır.

Gıda Etiketi Okuma ile Sağlık Algısı Bilgi Düzeyi Ölçeği: Geçerlik-güvenirlik çalışması olan bu anket formunda gida etiketi okumayla ilgili bilgi düzeylerini ölçmeye yönelik hazır yiyeceklerin gıda içeriği, gıda katkı maddelerinin toksik etkisi, alerjik gıdalar ve gıda etiketlerinin yararı hakkında 13 adet soru bulunmaktadır. Ayrıca anket, bu bilgi düzeylerinin davranışa geçirilmesini ölçen 13 adet soruyu da içermektedir. Anketteki; demografik veriler, gıda etiketi okuma bilgi düzeyi ve bu bilgi düzeyinin davranışa geçirilmesiyle ilgili toplam 38 soru, çalışmaya katılan 401 birey tarafından cevaplanmıştır. Anketin bilgi düzeyini ve davranışa geçirilmesini ölçen bölümlerinde doğru önermelerde katılıyorum=1, kararsızım $=0$, katılmıyorum $=0$ puan ile, yanlış önermelerde katılıyorum $=0$, kararsızım $=0$, katılmıyorum $=1$ puan olarak değerlendirilmiş ve toplam puan 26 olarak hesaplanmıştır.

Verilerin Toplanması: Bireylere çalışma hakkında bilgi verildikten sonra anketten elde edilen veriler 
sadece bilimsel amaçlı kullanılacak olup, herhangi bir ölçme ve değerlendirmeye tabii tutulmayacağ açıklaması yapılmıştır. Anket çevrimiçi ortamda gerçekleştirilmiştir.

Verilerin İstatistiksel Değerlendirmesi: Analizde IBM SPSS (Sosyal Bilimler için İstatistik Paketi) İstatistik 25 programı kullanılmıştır. Katılımcılar bilgi düzeyi ve davranışa geçirme genel puan ortalamalarının cinsiyet ve beslenme danışmanlığı alma/ almama değişkenlerine göre anlamlı olup olmadığını belirlemek için t-testi sonucunda grup ortalamalar arasındaki fark, BKİ ve eğitim durumu parametrelerine göre anlamlı bir farklılık olup olmadığını anlamak amacıyla tek yönlü varyans analizi (ANOVA) sonucunda grup ortalamaları arasındaki fark istatistiksel olarak değerlendirilmiştir. Veriler çarpıklık ve basıklık değerlerine göre normal dağılım göstermiştir. Çalışmada katılımcıların gıda etiketi hakkında bilgi düzeyi ile davranışa geçirme arasındaki ilişkiye bakılmıştır. Tanımlayıcı veriler ortalama ve standart sapma $(\overline{\mathrm{X}} \pm \mathrm{SS})$ olarak gösterilmiştir. Sonuçlar $\mathrm{p}<0,05$ anlamlılık düzeyinde $\% 95$ güven aralığında değerlendirilmiştir.

\section{BULGULAR}

Çalışmaya katılan 401 katılımcının "bilgi düzeyi" puan ortalaması $(9,42 \pm 2,10)$; "davranışa geçirme" puan ortalaması $(7,02 \pm 3,89)$ olarak saptanmıştır (Tablo 1).

Katılımcıların bilgi düzeyi puanları ortalamalarının beslenme danışmanlığı alma/almama değişkenine göre anlamlı bir farklılık gösterip göstermediğini belirlemek amaciyla yapılan t-testi sonucunda grup ortalamaları arasındaki farkın istatistiksel açıdan anlamlı bulunduğu tespit edilmiştir $(\mathrm{t}=0,264$ $\mathrm{p}=0,013<0,05)$. Danışmanlık alan bireylerin bilgi düzeyi puanları $(x=9,95)$, danışmanlık almayan bireylerin bilgi düzeyi puanlarından $(x=9,29)$ yüksektir. Katılımcıların davranışa geçirme puanları ortalamalarının danışmanlık alma/almama değişkenine göre grup ortalamaları arasındaki farkın istatistiksel açıdan anlamlı olmadı̆̆ saptanmıştır $(\mathrm{t}=0,146$; $\mathrm{p}=0,502>0,05$, Tablo 2).

Cinsiyet bazında bilgi düzeyi puanları ortalamaları incelendiğinde t-testi sonucuna göre grup ortalamaları arasındaki fark istatistiksel açıdan anlamlıdır $(\mathrm{t}=0,024 ; \mathrm{p}=0,00<0,05)$. Kadınların bilgi düzeyi puanları $(x=9,90)$, erkeklerin bilgi düzeyi puanlarından $(x=9,07)$ yüksek bulunmuştur. Katılımcıların cinsiyet değişkenine göre davranışa geçirme grup ortalamaları arasındaki fark istatistiksel açıdan anlamlı değildir $(\mathrm{t}=0,021 ; \mathrm{p}=0,63>0,05) . \mathrm{Bu}$ farklılı $\breve{g}_{1}$ belirlemek için t-testi kullanılmıştır (Tablo 3).

Katılımcıların bilgi düzeyi ve davranışa geçirme genel puanları ortalamalarının eğitim düzeyi değişkenine göre anlamlı bir farklılık gösterip göstermediğini belirlemek amaciyla yapılan tek yönlü varyans analizi (Anova) sonucunda grup ortalamaları arasındaki farkın istatistiksel açıdan anlamlı olduğu görülmüştür $(p<0,05)$. Farklılığın kaynağını test etmek için yapılan Post Hoc testlerinden GamesHowell testine göre lise düzeyindeki bireylerin bilgi düzeyi lisans düzeyindeki bireylerin bilgi düzeyinden, ortaokul statüsündeki bireylerin davranışa geçirme puan ortalaması lisans statüsündeki bireylerin davranışa geçirme puan ortalamasından farklılaşmaktadır. Lisans düzeyindeki bireylerin bilgi düzeyi puan ortalaması lise düzeyindekilere göre daha fazla olduğundan, öğrenim düzeyi arttıkça bilgi düzeyi artar sonucu, ortaokul düzeyindeki katılımcıların davranışa geçirme puan ortalaması lisans düzeyindeki katılımcılarınkinden daha fazla olduğu için, öğrenim düzeyi arttıkça davranışa geçirme azalır, sonucu ortaya çıkmıştır (Tablo 4).

Katılımcıların bilgi düzeyi ve davranışa geçirme genel puan ortalamaları BKİ değişkenine göre incelendiğinde hem bilgi düzeyi hem de davranış puan ortalamalarının yapılan tek yönlü varyans analizi (Anova) sonucunda, farkın istatistiksel açıdan anlamlı bulunmadığı saptanmıştır ( $\mathrm{p}>0,05)$ (Tablo 5) .

\section{TARTIŞMA VE SONUÇ}

$\mathrm{Bu}$ çalışmada yetişkin bireylerin etiket okuma bilgi düzeyi ile bu bilgilerini davranışa geçirmeleri arasındaki ilişki hakkında elde edilen sonuçlar ile literatürdeki bilgiler arasındaki benzerlikler ve farklar tartışılmıştır.

Zaidi ve Muhammad ${ }^{15}$ tarafindan gida etiketi okuma ile ilgili yapılan bir çalışmada, öğrenim düzeyi yüksek ve ailelerinde küçük çocuk bulunan bireylerin bile gıda etiketlerini okumadıklarını ve ancak almayı düşündükleri markaya dair üretim ve tüketim tarihine dikkat ettikleri tespit edilmiştir. Mevcut çalışmada da eğitim düzeyi yüksek olan bireylerin düşük olan bireylere göre davranışa geçirme puan ortalaması az olduğu için bu literatür bilgisi ile benzerlik göstermektedir.

Gün ve Orhan ${ }^{16}$ tarafından yapılan bir çalışmada kadınların erkeklere göre gida etiketi konusunda daha duyarlı bireyler olduğu, öğrenim düzeyi arttıkça etiket bilgi düzeylerinin ve birey tercihlerinin olumlu yönde değiştiği gözlenmiştir. Erzurum'da 400 kişinin katıldığı bir başka anket çalışması ile kadınların ve öğrenim düzeyi yüksek olanların etiket 
bilgilerine daha çok dikkat ettikleri bulunmuştur. ${ }^{17}$ Byrd-Bredbenner ve arkadaşlarr ${ }^{18}$ tarafından yapılan çalışmada kadınların erkeklere göre etiket bilgisini daha fazla okudukları; ancak öğrenim düzeyi düşük bireylerin ise etiket bilgisini okumadikları saptanmıştır. Literatürde yer alan bir çalışmada kadınların $\% 65,0$ 'inin, erkeklerin \%51,0'inin g1da etiketleri üzerindeki gıda öğesi değerlerini daha çok incelediği ve kadınların gıda etiketlerini erkeklerden daha çok okudukları belirtilmiştir. ${ }^{19}$ Güneş ve ark. ${ }^{20}$ eğitim düzeyinin artışı ile etiket okuma tutumunun da arttığını saptamışlardır. Mevcut çalışma cinsiyet faktörü ve etiket okuma bilgi düzeyi puan ortalaması üzerinde ilgili literatürdeki çalışmalar ile tutarlılık gösterse de davranışa geçirmede literatürdeki bilgilerle örtüşmemektedir. $\mathrm{Bu}$ farklılığın sebebi bireyden bireye değişebilecek olan kişisel özellikler ve bu özelliklerin g1da alırken tercih etme üzerine olan etkileri, ekonomik durumdan kaynaklı satın alım gücü olabilir.

Coşkun ve Kayışoğlu'nun ${ }^{12}$ yaptığı çalışmada cinsiyet ile şekerin sağlığa etkisine katılma oranı istatistiksel açıdan önemli bulunmuştur, fakat bu çalışmadaki analizler sonucunda "Kan şekerini yükseltme riskine karşı, etiketteki şeker cinsine ve miktarına dikkat ederim." ifadesine verilen cevapların cinsiyete göre farklılaşmadı $\breve{g}_{1}$ tespit edilmiştir.

Aksulu'nun ${ }^{21}$ konu ile ilgili çalışmasında insan sağl1ğını tehdit eden yă ve tuz miktarlarının yüksek olması tüketiciler tarafından çok önemli görülmezken, lifli gıdalar da önemli görülmemiştir. Aygen'in ${ }^{11}$ çalışmasında ise katılımcıların \%81'i çok yağlı, tuzlu, şekerli gıdalarla beslenmenin uzun vadede yüksek tansiyon, kalp krizi, kanser gibi rahatsızlıklara yol açabileceğini düşünmektedir. $\mathrm{Bu}$ çalışmada "Yüksek kolesterol rahatsızlığı yaşamamak için etiketteki doymuş yağ bilgilerine bakarım.”, “Tansiyon rahatsızlığı yaşamamak için etiketteki sodyum (tuz) bilgilerine dikkat ederim." ve "Sindirim sistemi hastalıklarını yaşamamak için etiketteki lif bilgilerine dikkat ederim." ifadelerine sirasıly \%48,6, \%46,9 ve $\% 42,9$ oranlarında katıliyorum cevabının verilmesi katılımcıların çoğunun gıdalardaki yağ, tuz ve lif miktarına önem verdiklerini göstermektedir.

Bu çalışmada "Hazır yiyeceklerde bulunan trans yağ asitleri kalp sağlığı için zararlıdır.” cümlesine katıl1yorum cevabını en çok veren bireylerin eğitim düzeylerinin lisans, bu cevabı en az verenlerin eğitim düzeylerinin ortaokul olduğu sonucuna varıldığından; bu çalışma, kolesterolün zararlı olduğunu savunanların oranının eğitim düzeyinin yükselmesi ile azaldığını tespit eden çalışma ile uyum göstermekte- dir. $^{22}$

Çalışmada "Etiketinde light ürün yazan yiyecekleri yağ içermediğini düşündüğüm için satın alıyorum.” ifadesine verilen cevapların analizi sonucunda, cinsiyet ile "light ürün" yazan yiyeceklerin yağ içermediği düşünüldüğünden satın alma davranışı arasındaki farkın istatistiksel olarak anlamlı olduğu tespit edilmiştir. Coşkun ve Kayışoğlu'nun ${ }^{12}$ yaptığı çalışmada ise etiketteki "light" ibaresi ile cinsiyet arasında istatistiksel açıdan önemli bir fark saptanmamıştır. Mevcut çalışmanın literatür ile örtüşmemesinin sebebi son iki yılda cinsiyetler arasındaki bilgi farkındalığının olası değişmesi ve bireylerin light ürünler ile ilgili bilgi düzeylerinin farklılığı olabilir. Bireylerin gıda etiketi okuma hakkındaki bilgi düzeyi ile bu bilginin davranışa geçirilmesi arasındaki ilişkiyi araştıran bu çalışmada beslenme danışmanlığ1 alan katılımcıların gitmeyen katılımcılara göre; kadın katılımcıların erkek katılımcılara göre daha çok bilgiye sahip olduğu fakat davranışta anlamlı bir fark olmadığı, eğitim dereceleri arasında bilgi düzeyinde ve davranışa geçirmede anlamlı bir fark bulunduğu, BKİ faktörüne göre ise anlamlı bir farkın olmadı̆̆ saptanmıştır.

Katılımcıların gida etiketi okuma hakkında bilgi sahibi olmalarına rağmen bu bilgilerini davranışa geçiremedikleri görüldüğünden obezitenin tedavisinin kalıcı olabilmesi için diyet tedavisinin yanında davranış değişikliği tedavisinin de uygulanması daha başarılı sonuçlar getirecektir.

Etik Komite Onayı: Araştırmanın yapılabilmesi için İstanbul Okan Üniversitesi Etik Kurulu'ndan izin alınmıştır (Tarih:14/06/2020, karar no: 56665618204.01.07).

Çıkar Çatışması: Yazarlar çıkar çatışması bildirmemektedir.

Yazar Katkılarl: Fikir - MG, ASK; Veri toplanması ve/veya işlemesi - MG, ASK; Analiz ve/veya yorum - MG, ASK; Yazıyı yazan - MG, ASK.

Hakem değerlendirmesi: Dış bağımsız.

Teşekkür: Yazarlar, çalışmaya katılan tüm bireylere teşekkür eder.

\section{KAYNAKLAR}

1. Cebeci A, Güneş FE. Türkiye ve Avrupa'daki tüketicilerin gıda etiketi okuma tutumlarını etkileyen faktörlerin değerlendirilmesi. GÜSBD. 2017;6(4):261-267.

2. Tüyben EE. Tüketicilerin gıda güvenilirliği yönünden etiket okuma alışkanlığı ve algısının değerlendirilmesi. Hacettepe Üniversitesi Sağlık 
Bilimleri Enstitüsü Toplu Beslenme Sistemleri Programı, Yüksek Lisans Tezi. Ankara, Türkiye. 2018.

3. Öztürk Duran EE. Obez ve normal ağırlıktaki bireylerin besin etiketi okuma alışkanlıkları. Gazi Üniversitesi Eğitim Bilimleri Enstitüsü Aile Ekonomisi ve Beslenme Eğitimi Anabilim Dalı, Yüksek Lisans Tezi. Ankara, Türkiye. 2014

4. Yavuz R, Tontuş HÖ. Erişkin, adolesan ve çocukluk yaş grubunda obeziteye klinik yaklaşım. J Exp Clin Med. 2013;30:69-74. doi:10.5835/jecm.omu.30.s1.010

5. Aslan D, Atilla S. Önemli bir sağlık sorunu: Şişmanlık. STED. 2002;11(5):169-171.

6. Bonsmann S, Wills J. Nutrition labeling to prevent obesity: reviewing the evidence from europe. Curr Obes Rep. 2012;1(3):134-140. doi:10.1007/s13679-012-0020-0

7. Roberto CA, Khandpur N. Improving the desing of nutrition labels to promote healthier food choices and resonable portion sizes. Int J Obes. 2014;38:25-33. doi:https://doi.org/10.1038/ ijo. 2014.86

8. Kaleli S. Sağlıklı beslenme ve besin etiketi okuma eğitimlerinin ortaokul öğrencilerinin besin tercihlerine etkisinin değerlendirilmesi. Hacettepe Üniversitesi Sağlık Bilimleri Enstitüsü Beslenme Bilimler Programı, Yüksek Lisans Tezi. Ankara, Türkiye. 2014.

9. Coşkun F, Kayışoğlu S. Besin etiketi okuma alışkanlıklarına tüketici yaşının etkisinin araştırılmas1. JHS. 2016;13(3):4876-4890. doi:10.14687/ jhs.v13i3.4089

10. Resmi Gazete. Türk gıda kodeksi gıda etiketleme ve tüketicileri bilgilendirme yönetmeliği. https:// www.resmigazete.gov.tr/eskiler/2017/01/ 20170126M1-6.htm. Erişim tarihi 31 Ağustos 2020.

11. Aygen FG. Tüketicilerin besin etiketi incelenmesi konusundaki tutum ve davranışları. İşletme Araştırmaları Dergisi. 2012;4(3):28-54.

12. Coşkun F, Kayışoğlu S. Besin etiketi okuma alışkanlıklarına ve etiket okumanın satın alma tercihlerine cinsiyetin etkisi: Tekirdağ ili örneği. Akademik Gida. 2018;16(4):422-430. doi:10.24323/akademik-gida.505518

13. TÜİK. Yaş Grubu ve Cinsiyete Göre Nüfus, 2000 Tablosu. http://www.tuik.gov.tr/ PreTablo.do?alt_id=1047. Erişim Tarihi 16 Mayis 2020.

14. Vergi Y. Besin etiketlerinin sağlık algısı üzerine etkisi. Marmara Üniversitesi Sağlık Bilimleri
Enstitüsü Beslenme ve Diyetetik Anabilim Dalı, Yüksek Lisans Tezi. İstanbul, Türkiye. 2018.

15.Zaidi A, Muhammad B. Awareness of Pakistani consumers towards nuritional labeling on product packaging in terms of buying behavior. IJBSS. 2012;3(6):97-103.

16. Gün İ, Orhan H. Süt ve ürünleri bireylerinin etiket bilgi düzeylerinin incelenmesi. JIST. 2011;1(1):45-51.

17. Sağlık E. Perakende gida ürünlerinde etiketin önemi, bireyler üzerindeki etkileri ve erzurum ölçeğinde bir alan araştırması. Atatürk Üniversitesi Sosyal Bilimler Enstitüsü İşletme Anabilim Dalı, Yüksek Lisans Tezi. Erzurum, Türkiye. 2003.

18. Byrd-Bredbenner C, Alfieri L, Kieferi L. The nutrition label knowledge and usage behaviours of women in the US. BNF Nutrition Bulletin. 2000;25(4):315-322. doi:10.1046/j.14673010.2000.00070.x

19. Micthel PM, Karslund MK, Finan A, Johnson J. Food label reading habits of WIC clients. JNEB. 1994;26(3):146-148.

20. Güneş FE, Aktaç Ş, İrem B, Korkmaz O. Tüketicilerin gida etiketlerine yönelik tutum ve davranışları. Akademik Gıda. 2014;12(3):30-37.

21. Aksulu İ. Tüketicide sağlığını koruma bilinci ve satın alma noktasında tüketici tutumları: Ambalajlı gıda ürünleri üzerine bir araştırma. İIBF Dergi. 2001;16(1):15-127.

22. Coşkun F, Kayışoğlu S. Eğitim düzeyinin besin etiketi okuma alışkanlıkları üzerine etkisi. JHS. $2018 ; 15(1): 486-498$. doi:10.14687/ jhs.v15i1.4840 
Tablo 1. Bilgi düzeyi ve davranışa geçirme puan ortalamaları.

\begin{tabular}{|l|c|c|c|c|}
\hline & n & Ort. \pm SS & $\begin{array}{c}\text { Minimum } \\
\text { puan }\end{array}$ & $\begin{array}{c}\text { Maksimum } \\
\text { puan }\end{array}$ \\
\hline Bilgi Düzeyi & 401 & $9,42 \pm 2,10$ & 1,00 & 13,00 \\
\hline Davranışa Geçirme & 401 & $7,02 \pm 3,89$ & 0,00 & 13,00 \\
\hline
\end{tabular}

n: Örneklem büyüklüğ̈̈; Ort.: Ortalama; SS: Standart sapma. 
Tablo 2. Bilgi düzeyi ve davranışa geçirme puan ortalamalarının beslenme danışmanlığı alma durumuna göre ortalamaları.

\begin{tabular}{|c|c|c|c|c|c|}
\hline & Grup & $\mathbf{n}$ & Ort. $\pm S S$ & İstatiksel test & $\mathbf{p}$ \\
\hline \multirow[t]{2}{*}{ Bilgi Düzeyi } & Danışmanlık alan & 79 & $9,95 \pm 1,98$ & \multirow[t]{2}{*}{ t- 0,264} & \multirow[t]{2}{*}{0,013} \\
\hline & Danışmanlık almayan & 322 & $9,29 \pm 2,11$ & & \\
\hline \multirow[t]{2}{*}{ Davranışa Geçirme } & Danışmanlık alan & 79 & $7,28 \pm 3,67$ & \multirow[t]{2}{*}{ t- 0,146} & \multirow[t]{2}{*}{0,502} \\
\hline & Danışmanlık almayan & 322 & $6,95 \pm 3,95$ & & \\
\hline
\end{tabular}

n: Örneklem büyüklüğ̈̈; Ort.: Ortalama; SS: Standart sapma; t: t testi; p: Olasılık. 
Tablo 3. Bilgi düzeyi ve davranışa geçirme puan ortalamalarının cinsiyete göre ortalamaları.

\begin{tabular}{|l|l|l|l|l|l|}
\hline & Grup & $\mathbf{n}$ & Ort. \pm SS & İstatiksel test & p \\
\hline \multirow{2}{*}{ Bilgi Düzeyi } & Kadın & 171 & $9,90 \pm 1,80$ & \multirow{2}{*}{ t- 0,024} & \multirow{2}{*}{0,00} \\
\cline { 2 - 5 } & Erkek & 230 & $9,07 \pm 2,24$ & & \\
\hline \multirow{2}{*}{ Davranışa Geçirme } & Kadın & 171 & $6,91 \pm 3,65$ & \multirow{2}{*}{ t- 0,021} & \multirow{2}{*}{0,63} \\
\cline { 2 - 4 } & Erkek & 230 & $7,10 \pm 4,06$ & & \\
\hline
\end{tabular}

n: Örneklem büyüklüğ̈̈; Ort.: Ortalama; SS: Standart sapma; t: t testi; p: Olasılık. 
Tablo 4. Bilgi düzeyi ve davranışa geçirme puan ortalamalarının eğitim düzeyine göre ortalamaları.

\begin{tabular}{|c|c|c|c|c|c|}
\hline & Grup & $\mathbf{n}$ & Ort. \pm SS & İstatiksel test & $\mathbf{p}$ \\
\hline \multirow[t]{6}{*}{ Bilgi Düzeyi } & İlkokul & 25 & $9,08 \pm 2,40$ & \multirow[t]{6}{*}{ F- 3,58 } & \multirow[t]{6}{*}{0,004} \\
\hline & Ortaokul & 25 & $8,92 \pm 2,68$ & & \\
\hline & Lise & 93 & $8,86 \pm 2,32$ & & \\
\hline & Ön lisans & 48 & $9,17 \pm 1,78$ & & \\
\hline & Lisans & 169 & $9,82 \pm 1,82$ & & \\
\hline & Yüksek lisans/doktora & 41 & $9,85 \pm 2,14$ & & \\
\hline \multirow{6}{*}{ Davranışa Geçirme } & İlkokul & 25 & $7,84 \pm 4,58$ & \multirow[t]{6}{*}{ F- 2,91 } & \multirow[t]{6}{*}{0,014} \\
\hline & Ortaokul & 25 & $8,92 \pm 3,93$ & & \\
\hline & Lise & 93 & $7,06 \pm 4,31$ & & \\
\hline & Ön lisans & 48 & $7,46 \pm 3,48$ & & \\
\hline & Lisans & 169 & $6,31 \pm 3,60$ & & \\
\hline & Yüksek lisans/doktora & 41 & $7,61 \pm 3,56$ & & \\
\hline
\end{tabular}

n: Örneklem büyüklüğ̈̈; Ort.: Ortalama; SS: Standart sapma; F: F istatistiği; p: Olasılık. 
Tablo 5. Bilgi düzeyi ve davranışa geçirme puan ortalamalarının BKİ'ye göre ortalamaları.

\begin{tabular}{|c|c|c|c|c|c|}
\hline & Grup & $\mathbf{n}$ & Ort. \pm SS & İstatiksel test & $\mathbf{p}$ \\
\hline \multirow[t]{4}{*}{ Bilgi Düzeyi } & $<18,4$ & 10 & $9,50 \pm 1,51$ & \multirow[t]{4}{*}{ F- 0,027} & \multirow[t]{4}{*}{0,994} \\
\hline & $18,5-24,9$ & 148 & $9,45 \pm 2,13$ & & \\
\hline & $25-29,9$ & 166 & $9,39 \pm 2,11$ & & \\
\hline & $\geq 30$ & 77 & $9,42 \pm 2,12$ & & \\
\hline \multirow[t]{4}{*}{ Davranışa Geçirme } & $<18,4$ & 10 & $7,40 \pm 3,75$ & \multirow[t]{4}{*}{ F- 0,362} & \multirow[t]{4}{*}{0,780} \\
\hline & $18,5-24,9$ & 148 & $6,76 \pm 3,70$ & & \\
\hline & $25-29,9$ & 166 & $7,18 \pm 3,95$ & & \\
\hline & $\geq 30$ & 77 & $7,10 \pm 4,16$ & & \\
\hline
\end{tabular}

n: Örneklem büyüklüğü; Ort.: Ortalama; SS: Standart sapma; F: F istatistiği; p: Olasılık. 